\title{
Salvaguarda do acervo documental da Reserva Florestal Ducke - Manaus-AM: registros de uma experiência
}

\author{
Eliane Oliveira de Lima Freire \\ Instituto Nacional de Pesquisas da Amazônia (Inpa). \\ Doutorado em histoire sociale. Université Paris 1 (Panthéon- \\ Sorbonne), Sorbonne, França. \\ E-mail:eliane723@hotmail.com
}

\author{
Rodolfo Almeida de Azevedo \\ Univesidade Federal do Amazonas (Ufam). Instituto \\ Nacional de Pesquisas da Amazônia (Inpa). Bolsista de \\ iniciação científica Inpa/CNPq. \\ E-mail: almeida.azevedo@hotmail.com
}

\section{Resumo}

A Reserva Florestal Ducke é uma das mais importantes bases de pesquisa do Instituto Nacional de Pesquisas da Amazônia (Inpa). Embora a reserva se destaque no meio científico, seus documentos produzidos e acumulados ao longo de sua existência encontravam-se desorganizados. Com a realização de intensa coleta documental, os arquivos foram resgatados e salvaguardados. No presente artigo, relatam-se os resultados desta experiência. A salvaguarda do acervo foi realizada em três etapas: primeira - recolha dos documentos; segunda digitalização do material recolhido e terceira - compilação de instrumentos de pesquisa. Com o material coletado e organizado, criou-se uma edição de fontes documentais contendo documentos manuscritos e impressos e dois catálogos, sendo um documental e outro bibliográfico. $\mathrm{O}$ acervo da Reserva Ducke oferece múltiplas possibilidades de estudos temáticos com base no conteúdo dos documentos. Neste sentido, foram realizados alguns apontamentos temáticos das peças documentais, entre os quais se destacam: Adolfo Ducke, criação da reserva, infraestrutura, as pesquisas, ocupações ilegais, degradação versus preservação e jardim botânico.

\section{Palavras-chave}

Digitalização de acervos. Reserva Florestal Ducke. Preservação de documentos.

\author{
Safeguard documentary collection of forest \\ reserve Ducke - Manaus-AM: records of an \\ experience
}

\begin{abstract}
The Ducke Forest Reserve (Reserva Florestal Ducke) is one of the most important research bases of the National Research Institute of Amazonia (Instituto Nacional e Pesuisas da Amazônia - INPA). Although this reserve stands out in the scientific milieu, the documents produced and accumulated during its existence were disorganized. By undertaking an intense collection of documents, these archives were rescued and safeguarded. In the present article, the results of this experience are related. The safeguarding of the document patrimony of the Ducke Reserve was undertaken in three stages: first - collecting documents; second - putting the material collected into digital notation; and third - the compilation of research instruments. Having collected and organized the material, a source of edition was carried out as well as two documentary and bibliographic catalogues The documentary patrimony of the Ducke Reserve presented multiple possibilities of thematic studies based on the contents of the documents. In this sense, some thematic annotations were made about the documents, emphasizing the following: Adolfo Ducke, creation of the reserve, infrastructure, research, illegal occupation, degradation versus preservation of the botanical garden. Finally, the results of this research are expected to disseminate and facilitate public access to the documents on Ducke Reserve and consequently reveal hidden and forgotten facts along its existence.
\end{abstract}

\section{Keywords}

Digitization of collections. Forest Reserve Ducke. Preservation of documents. 


\section{INTRODUÇÃO ${ }^{1}$}

São poucos os estudos no Brasil que se preocupam com a salvaguarda da memória patrimonial das florestas. Como forma de contribuir no suprimento desta lacuna, a informação contida no acervo documental de uma reserva da Floresta Amazônica Central foi recuperado. Trata-se da Reserva Florestal Ducke, situada no perímetro urbano da periferia de Manaus - AM (figura 1), uma das mais importantes bases de pesquisa do Instituto Nacional de Pesquisas da Amazônia (Inpa), unidade de pesquisa e ensino localizada na Amazônia e subordinada ao Ministério da Ciência e Tecnologia (MCT). Este Instituto se destaca nacional e internacionalmente como centro de excelência em pesquisas regionais com ênfase em biodiversidade.

A Reserva Ducke recebeu este nome em memória ao seu idealizador, o naturalista Adolfo Ducke (1876-1959), de origem austro-húngara, natural de Trieste. Ele fez diversas expedições científicas pelo

\section{FIGURA 1}

\section{Imagem digital da área da Reserva Florestal Ducke}

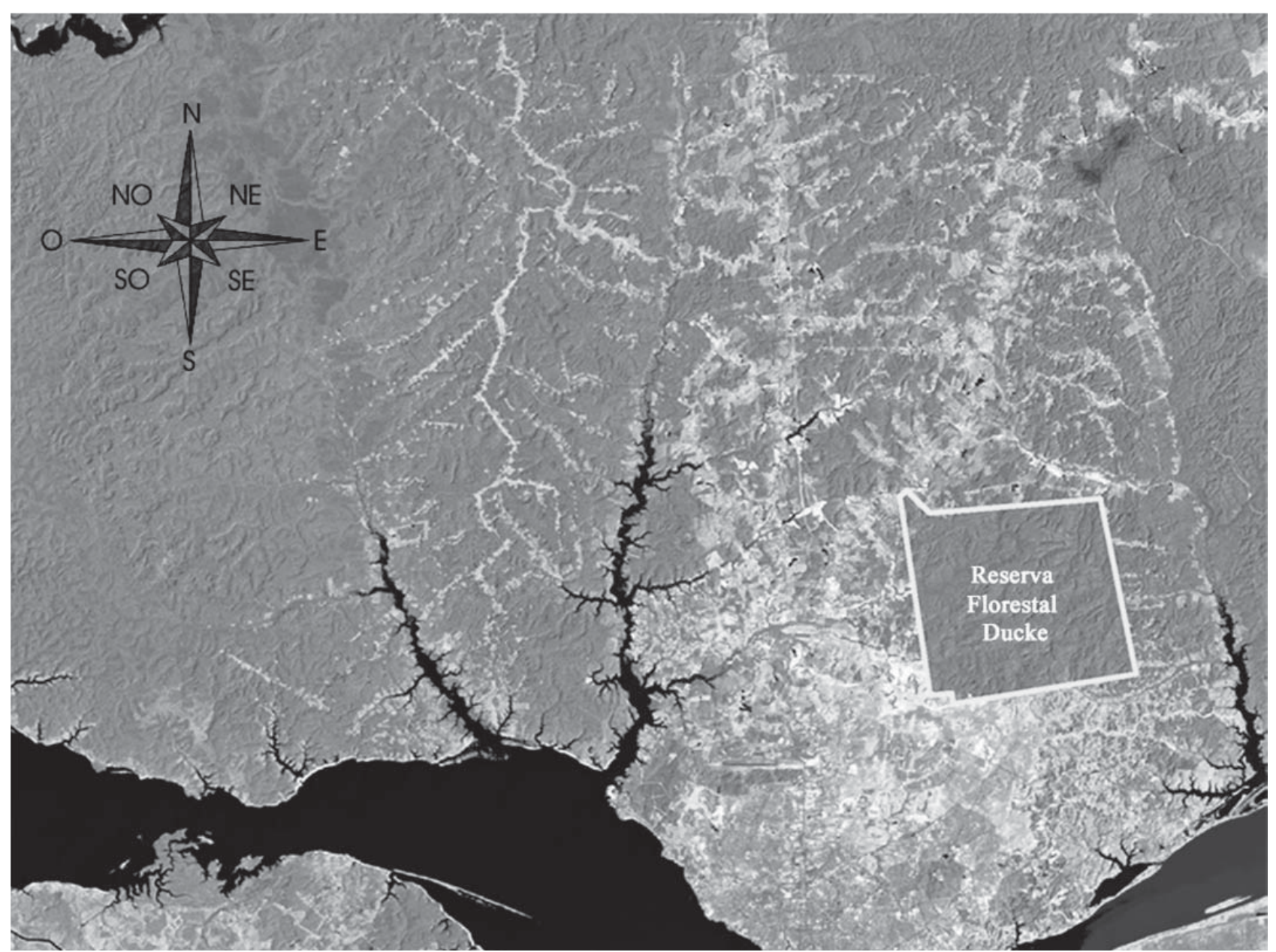

Fonte: Siglab/Inpa, 2006.

\footnotetext{
${ }^{1}$ Mais detalhes sobre aspectos históricos da Reserva Ducke ver FREIRE, Eliane Oliveira de Lima. Do sonho à realidade: a criação da Reserva Ducke. In: XXV Simpósio Nacional de História: História e Ética - Anais Eletrônico do Simpósio. Fortaleza, julho de 2009, pp. 1-10.
} 
Brasil, estudando inúmeras espécies e gêneros novos de plantas. Em uma de suas expedições a Manaus, reconheceu a diversidade da floresta para estudos científicos e, por isso, recomendou que fosse criada neste local uma área de preservação permanente. Em 1948, Adolfo Ducke indicou a área para que fosse criada a reserva. Porém a área desprotegida foi degradada pela ação do extrativismo. Somente em 1957 foi escolhida pelo Inpa, sob orientação do naturalista, uma nova área. Atualmente a reserva encontra-se ameaçada pela expansão urbana de Manaus.

Registros em relatórios e inventários mostram que desde a segunda metade da década de 50 foram feitas as primeiras coletas botânicas na área da Reserva Ducke. Até 1972 a Reserva foi destinada a experimentos de silviculturas. Ali foram realizados plantios de espécies com importância econômica, ocupando menos de $2 \%$ da área total. Após esse ano as atividades de plantios foram encerradas. A partir daí as pesquisas ficaram concentradas a noroeste da reserva, em espaço que corresponde a aproximadamente $1 / 5 \mathrm{da}$ área total, onde se situam os alojamentos e um sistema de trilhas.

A área para a criação desta reserva foi doada ao Inpa pelo Governo do Estado do Amazonas em 28 de novembro de 1962, pela Lei ${ }^{\circ} 41$, publicada no Diário Oficial de 16 de fevereiro de 1963 (ver fotografia aérea da Reserva Ducke na figura 2). Trata-se de imagem aérea que mostra as instalações existentes na reserva: na parte inferior do lado direito ficam três edificações que são ligadas por uma estrada de terra com à estação meteorológica, localizada na parte superior esquerda da imagem.

\section{FIGURA 2}

\section{Acervo: Biblioteca do Inpa}

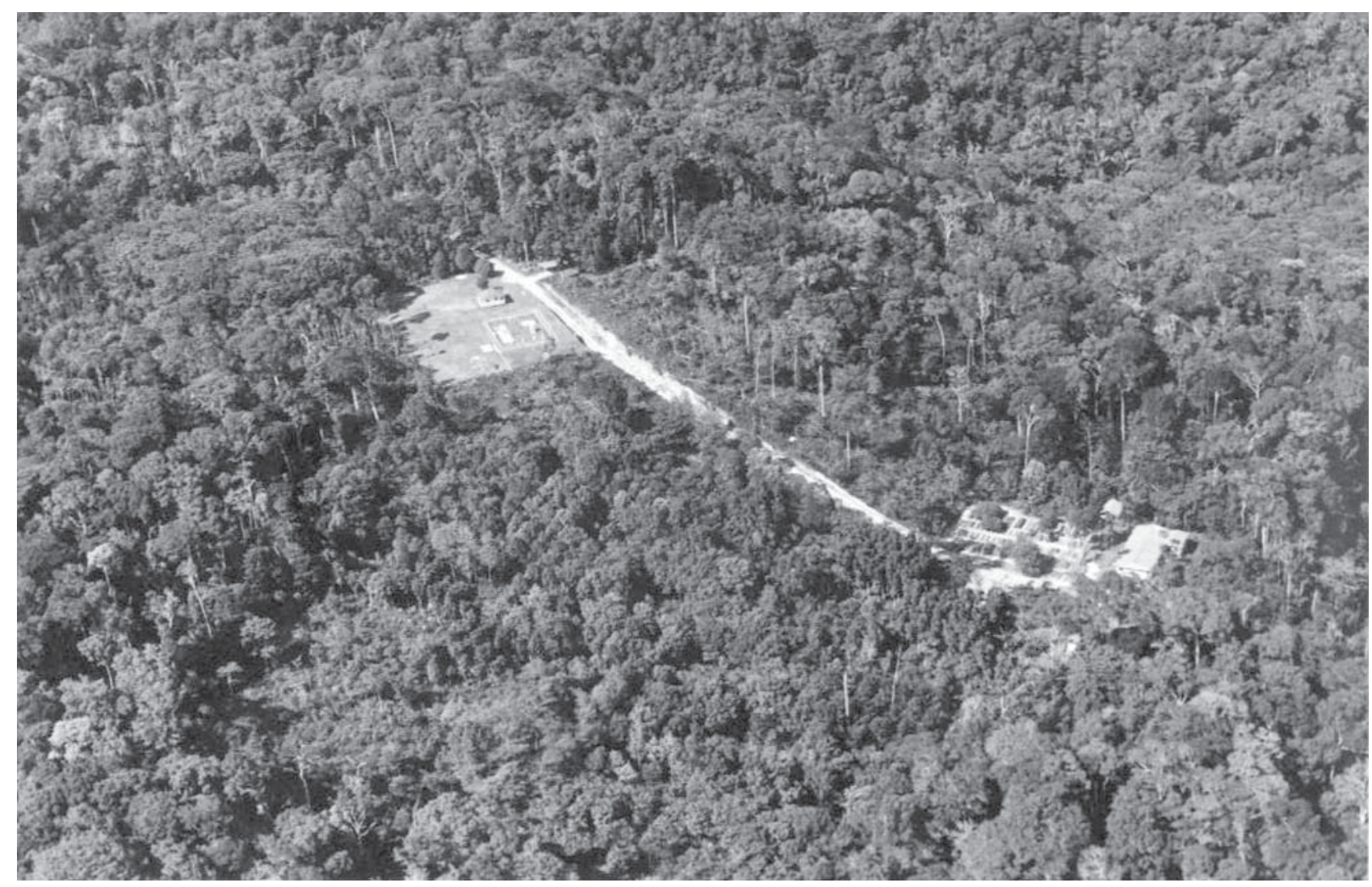

Fonte: Fotógrafo desconhecido, s/d. Preto e Branco: 18 x 12 cm. 
Segundo os pesquisadores do Inpa, esta reserva é um dos biomas mais bem estudados da Floresta Amazônica Central de terra firme, e ali se encontra grande diversidade de espécies da fauna e da flora. A reserva Ducke foi objeto de inúmeras pesquisas, entre as quais destacam-se: pesquisa sobre a malária simiana, avaliações limnológicas, inventários de vetores e reservatórios naturais de Leishmaniose e Doença de Chagas, entre outras (FONSECA, apud RIBEIRO et. al. 1999). Junte-se a isso o fato de que seus guias de campo têm um conhecimento mais completo sobre a flora e fauna da região. (RIBEIRO et al., 1999; MARTINS \& OLIVEIRA, 1998; ADIS, 2002; LIMA et. al., 2006; LAURIE, 2008).

Embora a Reserva Ducke se destaque no meio científico como uma importante base de pesquisa, os documentos produzidos e ao longo de sua existência encontravam-se completamente desorganizados e distribuídos em diversos setores do Inpa, bibliotecas e arquivos públicos da cidade de Manaus.

Como o Inpa ainda não dispõe de arquivo permanente para acondicionar seu acervo e ao mesmo tempo dispô-lo para consulta pública, o Núcleo de Pesquisas de Ciências Humanas e Sociais (NPCHS), do Laboratório de Psicologia e Educação Ambiental (Lapsea/Inpa), percebeu a importância do acervo, não somente para resgatar a memória patrimonial da reserva para a história da ciência na Amazônia, mas especialmente pelo fato de a floresta amazônica estar diretamente ligada às discussões ambientais que envolvem a qualidade de vida no planeta Terra. O LAPSEA desenvolveu entre abril de 2007 a março de 2010 o projeto intitulado "Resgate da História SocioAmbiental da Reserva Florestal Ducke", e os resultados metodológicos desta experiência são aqui apresentados.

\section{METODOLOGIA}

A salvaguarda do acervo documental da Reserva Florestal Ducke foi realizada em três fases, detalhadas a seguir.
A primeira etapa tratou da pesquisa de campo, iniciada com uma busca bibliográfica sobre os procedimentos metodológicos a serem seguidos. Posteriormente foi feita a recolha dos documentos impressos, manuscritos e iconográficos, nos seguintes locais: da recolha dos documentos impressos, manuscritos e iconográficos, que foi realizada no Instituto Geográfico Histórico do Amazonas (IGHA), Biblioteca da Universidade Federal do Amazonas (Ufam), Biblioteca do Estado do Amazonas, Arquivo Público do Estado do Amazonas, Arquivo do Diário Oficial do Estado do Amazonas, Biblioteca do Inpa, Biblioteca Arthur Reis, Acervo da Divisão de Suporte de Estações e Reserva (DSER/Inpa), Acervo Digital do Laboratório de Psicologia e Educação Ambiental (Lapsea/Inpa), Acervo Digital do Siglab/Inpa, acervo do Setor de Patrimônio/Inpa, bem como acervos particulares do Botânico William Rodrigues e do fotógrafo Anselmo D`Affonseca.

A segunda etapa tratou da digitalização do material recolhido. Esse processo representa uma das ferramentas essenciais ao acesso e à difusão dos acervos arquivísticos, contribuindo para a sua preservação, uma vez que "restringe o manuseio aos originais, constituindo-se como instrumento capaz de dar acesso simultâneo local ou remoto aos seus representantes digitais" (ARQUIVO NACIONAL, 2010 , p.4). Os documentos que não estavam em boas condições de conservação foram transcritos ou restaurados (figuras 3, 4, 5 e 6 ). Outros foram transcritos segundo as Normas Técnicas Para Transcrição e Edição de Documentos Manuscritos (figura 4). Quanto aos impressos, também foram transcritos apenas quando as cópias dos originais se encontravam em estado precário de conservação ou visibilidade, principalmente se dificultavam a leitura.

Em alguns casos, as cópias dos originais foram submetidas à restauração, utilizando-se do programa Adobe Photoshop. Os devidos cuidados para não deformar o documento nem rasurá-lo foram tomados, evitando o embelezamento desmedido que permite este programa, ocasionando a perda da

Ci. Inf., Brasília, DF, v. 39 n. 2, p.101-114, maio/ago., 2010 
originalidade do documento. As restaurações foram realizadas apenas quando não havia texto no local, suavizando manchas e reconstituindo corroídos, rasgaduras e sujeiras. Finalmente, os documentos digitalizados foram armazenados em arquivos do Microsoft Office Word, Adobe Reader e JPEG.

O objetivo dessa etapa também foi de preservação dos documentos originais, pois foi interrompido o processo de deteriorização progressiva em que se encontravam. Estabilizar seria, portanto, interromper um processo que estivesse deteriorando o suporte e/ou seus agregados, com procedimentos mínimos de intervenção. Os procedimentos foram de higienização, retirada de materiais metálicos, bem como seu devido acondicionamento em caixaarquivo em seus respectivos lugares.

A terceira e última etapa tratou da compilação de instrumentos de pesquisa. Com o material coletado e organizado criou-se uma edição de fontes e dois catálogos, sendo um documental e outro bibliográfico. Ambos são descritos a seguir.

A edição de fontes teve como base as instruções de Araújo (1985), Bellotto (2004), Glénisson (1961). Os documentos originais foram publicados na íntegra, contendo transcrição paleográfica e reprodução apenas dos documentos de valor histórico de difícil acesso e em risco de perda ou de autodestruição. Os devidos cuidados foram tomados com os problemas de seleção (crítica geral), leitura (paleografia), análise (diplomática), intelecção (gramática, lexicografia), identificação de datas (cronologia) ou nomes (onomástico, biografia, genealogia, geografia histórica), determinação dos fatos (história geral, biografia, pesquisa de fontes paralelas), etc. Foram elaborados os índices com base em estudos nos campos da paleografia, da diplomática, da ecdótica e da heurística. Além disso, a edição foi precedida de textos preliminares, acompanhados de estudos introdutórios e notas em que se indica o objetivo da publicação, remetendo-a quanto aos critérios e convenções para Normas Técnicas para Transcrição e Edição de Documentos Manuscritos.
QUADRO 1

Ficha catalográfica para documentos históricos

\begin{tabular}{|c|c|c|}
\hline \multicolumn{3}{|l|}{$\begin{array}{c}\text { ESPÉCIE } \\
\text { DOCUMENTAL: }\end{array}$} \\
\hline & & \\
\hline DESTINATÁRIO: & & \\
\hline FUNÇÃO: & & \\
\hline AÇÃ̃O: & & \\
\hline DATA TÓPICA: & $\begin{array}{c}\text { DATA } \\
\text { CRONOLÓGICA: }\end{array}$ & \\
\hline ASSINATURA: & $\begin{array}{l}\text { QUANTIDADE } \\
\text { DE PÁGINAS: }\end{array}$ & \\
\hline $\begin{array}{c}\text { ANEXOS ou } \\
\text { OBSERVACÕES: }\end{array}$ & & \\
\hline $\begin{array}{l}\text { NOTAÇÃO DE } \\
\text { LOCALIZAÇĀO: }\end{array}$ & & \\
\hline
\end{tabular}

Fonte: Elaboração do autor.

O catálogo documental refere-se ao acervo da edição de fontes. Sua elaboração teve como base Bellotto (2002, 2004), que tem como referência a Norma International Standard Archival Description (general) - ISAD $(G)$ - cuja tradução, na terminologia brasileira, consagrou-se como Norma Geral Internacional de Descrição Arquivística.

O catálogo foi iniciado com a confecção de fichas catalográficas, que servem para agilizar o processo de catalogação, necessário devido à diversidade de documentos pertencentes ao acervo, sendo preciso confeccionar três tipos de fichas: ficha 1, que objetivava catalogar documentos históricos, como cartas, relatórios, memorandos, entre outros, contendo os seguintes itens: espécie documental, emissor, destinatário, função, ação, data tópica, data cronológica, um espaço para especificar se o documento possui assinatura, o número de páginas, um espaço para observações e a sua localização no acervo; a ficha 2 foi feita visando a catalogar documentos iconográficos, e nela constam os seguintes itens: título, a descrição física da imagem, o fotógrafo, data tópica, data cronológica, descrição da imagem, estado de conservação e sua localização no acervo; e a ficha 3 foi utilizada para catalogar obras bibliográficas, contendo os seguintes itens: nome do autor, título da obra, data tópica, data cronológica, editora, descrição física e sua localização no acervo. Também foi feito um manual para o preenchimento de cada ficha, objetivando auxiliar no ato da catalogação. 
Faz-se necessário ressaltar que não se trata apenas de coleta de dados, pois, nas três fichas, foi necessário resumir em poucas palavras o conteúdo do documento, sendo importante estar situado no contexto de produção do documento, pois em muitos casos, trata-se de perguntas e/ou respostas trazendo lacunas que necessitam de novas pesquisas para serem respondidas.

Após a fase da catalogação, ou seja, a descrição por série, documento por documento utilizando as fichas catalográficas, foram elaborados três índices: remissivo, toponímico e antroponímico, visando à melhor organização e acessibilidade do catálogo. Os dados coletados foram quantificados em uma representação gráfica. Também os dados foram analisados, objetivando conhecer quais tipos de produção documental o acervo possui e quais os principais conteúdos tratados nesses documentos sobre a Reserva Ducke.

Quanto ao catálogo bibliográfico, restringiu-se ao levantamento de teses de doutorado e dissertações de mestrado referente à Reserva Ducke, aprovadas pelo Programa de Pós-Graduação Convênio Inpa e Universidade Federal do Amazonas (Ufam) de 1973 até 2006. Na ocasião, foram consultados o fichário manual e banco de dados on-line da Biblioteca do Inpa, fichário da Biblioteca da Universidade Federal da Amazônia (Ufam), Catálogo de Dissertações e Teses do Programa de Pós-graduação em Biologia Tropical e Recursos Naturais e banco de dados online do Programa de Pesquisas em Biodiversidade (PPBio). Com a bibliografia identificada, registraramse referências importantes (autor, título, ano, curso, número de páginas) e resumo. Além disso, foi elaborada uma introdução enfatizando os objetivos, bem como a quantificação do levantamento.

\section{A ELABORAÇÃO DOS INSTRUMENTOS DE PESQUISA}

Recolheu-se um total de 278 documentos, entre os quais constam documentos iconográficos, como pode ser observado nas figuras $(3,4,5$ e 6), além de 69 trabalhos acadêmicos do Programa de Pós-Graduação Inpa/Ufam. Como resultado final foram elaborados três instrumentos de pesquisa: uma edição de fontes documentais, um catálogo documental e um catálogo bibliográfico. Com o intuito de facilitar o acesso do usuário aos documentos referentes à Reserva Florestal Ducke, os instrumentos de pesquisa foram elaborados em duas versões: impressa e digital.

\section{QUADRO 2}

\section{Ficha catalográfica para obras bibliográficas}

\begin{tabular}{|c|l|}
\hline NOME DO AUTOR (S) & \\
\hline TÍTULO DA OBRA & \\
\hline DATA TÓPICA & \\
\hline EDITORA & \\
\hline DATA CRONOLÓGICA & \\
\hline DESCRIÇÃO FÍSICA & \\
\hline NOTAÇÃO DE & \\
LOCALICAÇÃO & \\
\hline
\end{tabular}

Fonte: Elaboração do autor.

\section{Edição de fontes}

A edição de fontes recebeu como título "Edição de Fontes para a História Ambiental da Reserva Florestal Ducke". Ela é composta por dois volumes com o total de 645 páginas, que introdução com breve referencial teórico, contendo as definições de fonte histórica, heurística e edição de fontes. Logo após, seguem as informações de como se processou sua elaboração, com relato detalhado de toda a fase da heurística, desde a investigação do paradeiro das fontes, bem como a coleta, seleção, a restauração das cópias digitalizadas, acondicionamento adequado e organização sob a forma impressa e digital. Por fim, há índices remissivo, toponímico e antroponímico, com a enumeração do documento correspondente.

Para consultar esta edição de fontes foram elaborados os índices, aos quais o usuário deve se dirigir sequencialmente ao remissivo (assunto), toponímico (nomes de instituições), antroponímico (nomes de pessoas) e escolher o termo de seu interesse. A partir da enumeração de cada documento que ali se encontra, deve se dirigir às cópias dos mesmos a partir do número correspondente. Os consulentes podem ainda obter cópias destes documentos através do acervo digital.

Ci. Inf., Brasília, DF, v. 39 n. 2, p.101-114, maio/ago., 2010 


\section{Catálogo Documental}

O catálogo documental tem como título "Catálogo de Fontes Históricas da Reserva Florestal Ducke", Azevedo R. A. de (2009), no qual foi descrito unitariamente cada um dos 278 documentos pertencentes ao acervo da Reserva Florestal Ducke, que se encontra organizado sob a forma de edição de fontes. A organização dos dados dos documentos catalogados pode ser observada pelos três verbetes (1, 2 e 3), que e contêm os dados dos primeiros documentos, que são: um documento iconográfico, representado pelo verbete 1 , uma obra bibliográfica representado pelo verbete 2 , e uma carta de Adolfo Ducke, representada pelo verbete 3 .

\section{FIGURA 3}

\section{Carta do naturalista Adolfo Ducke ao botânico William Rodrigues}

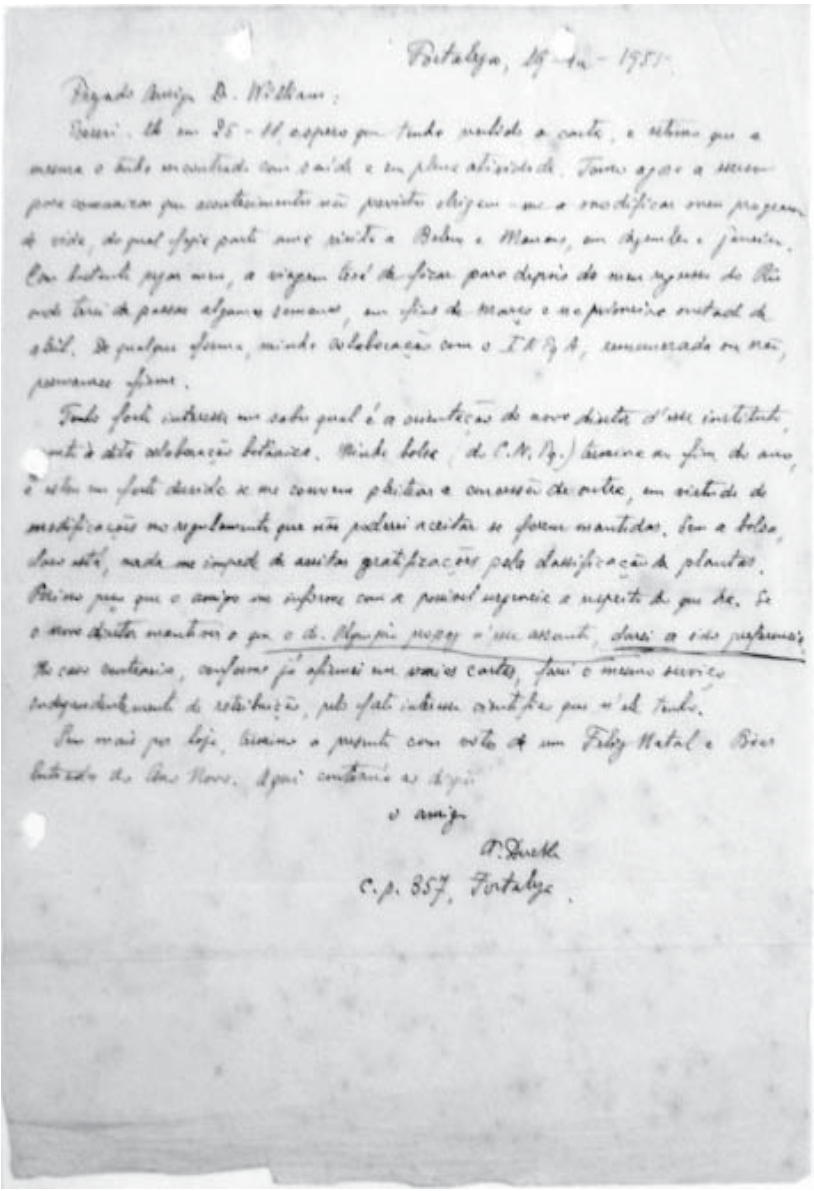

FIGURA 4

Transcrição da carta de Adolfo Ducke a William Rodrigues, segundo as Normas Técnicas para Transcrição e Edição de Documentos Manuscritos

Fortaleza, 19-12-1955 (01)

Prezado amigo Dr.William: (02)

Escrevi-lhe em 25-11, espero que tenha recebido a carta, e estimo que a (03) mesma o tenha encontrado com saúde e em plena atividade. Toma agora a mesma(04) para comunicar que acontecimentos não previstos obrigam-me a modificar meu (05) projeto(05)

de vida, do qual fazia parte uma visita a Belém e Manaus, em dezembro e janeiro.(06) Com bastante pesar meu, a viagem terá de ficar depois do meu regresso do Rio ( 07 ) onde terei de passar algumas semanas, em fins de março e na primeira metade de(08) abril. De qualquer forma, minha colaboraçăa com o INPQA, remunerada ou não(09) permanece firme.(10)

Tenho forte interesse em saber qual é a orientação do novo diretor d'esse instituto(11) [quantol a dita colaboraçăo botânica. Minha bolsa (do C.N. Pq) termina no fim do(12) ano, (12)

e estive em forte duvida se me convém pleitear a concessão de outra, em virtude de(13) modificaçăo no regulamento que năo poderei aceitar se forem mantidas sem a bolsa,(14) claro está, nada me impede de aceitar gratificacōoses pela classificaçäos pla toolsa, claro está, nada me impede de aceitar gratificaçōes pela classificação de plantas.(15) hả. Se(16)

o nosso diretor mantiver o que o dr. Olympio propoz n'esse assunto darei a isso (17) preferência (17)

no caso contrario, conforme já afirmei em varias cartas, farei o mesmo serviço (18) independentemente de retribuição pelo forte interesse cientifico que n'ele tenho(19) Sem mais por hoje, termino a presente com votos de um Feliz Natal e Bien(20) entoados do Ano Novo. Aqui continuo a dispor(21)

o amigo(22)

c.p. 357 , Fortaleza(24

\section{FIGURA 5}

Título de doação de terras denominado "Reserva Florestal Ducke", do Governo do Estado do Amazonas ao Instituto Nacional de Pesquisas da Amazônia (Inpa)

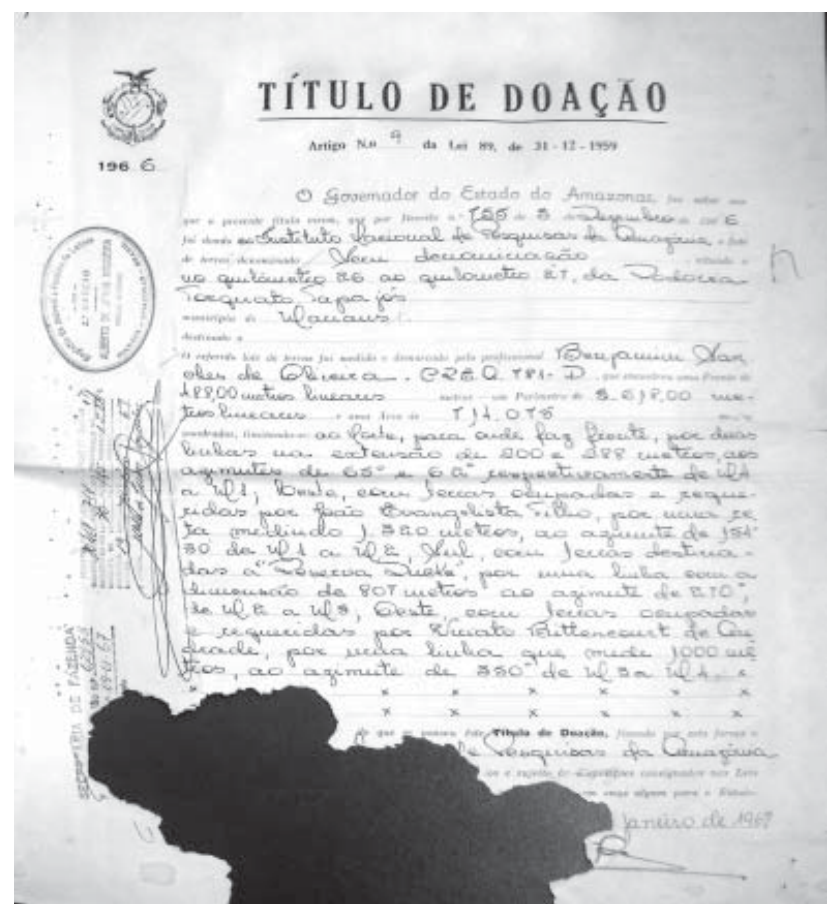


FIGURA 6

Transcrição do título de doação de terras da "Reserva Florestal Ducke", do Governo do Estado do Amazonas ao Instituto Nacional de Pesquisas da Amazônia (Inpa)

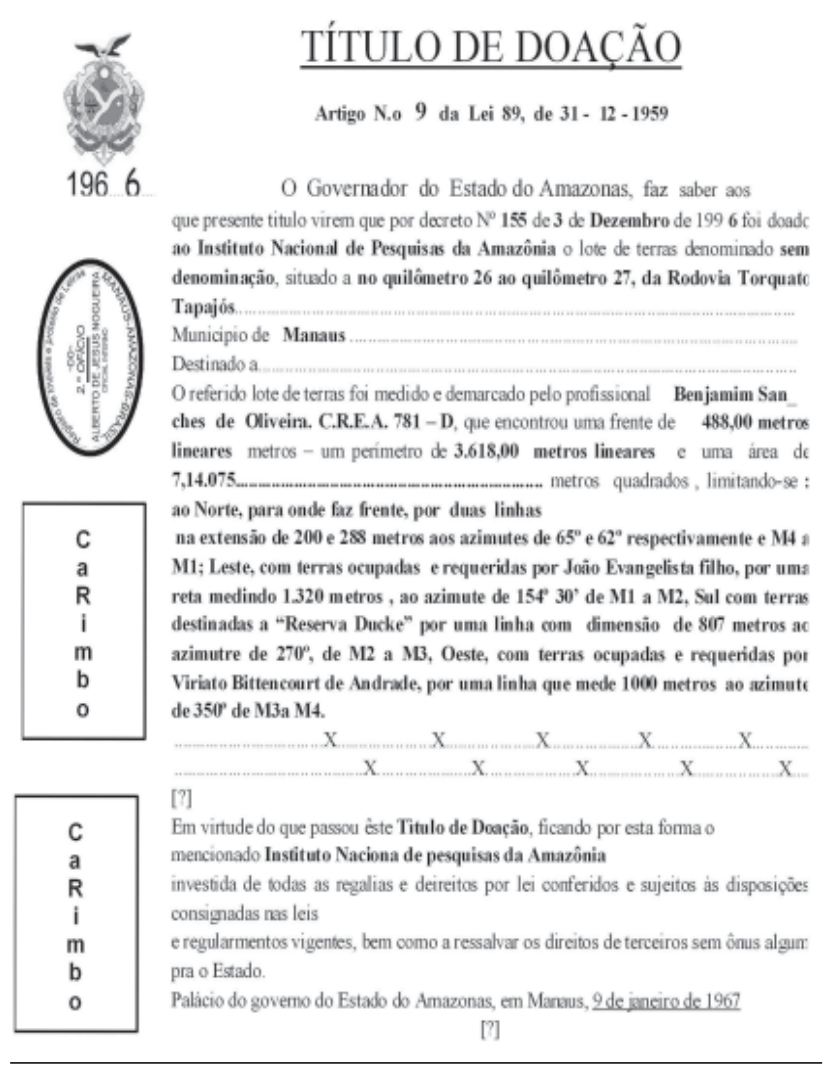

\section{VERBETE 1}

- Adolfo Ducke. Preto e Branca, 16,5 x 24 cm. G. Leite. s/d. 1960. Litografia do rosto de Adolfo Ducke. Bom estado de conservação.

Documento 1
VERBETE 3

- Carta, de Adolfo Ducke, a Dr. Olympio Oliveira Ribeiro da Fonseca Filho, pedindo o interesse do Dr. Olympio sobre a localização do senhor Joaquim Chagas, que havia ficado encarregado de vigiar o exemplar da S. Froesii, na mata do Tarumã, pois não havia mais tido notícia sobre o mesmo. Fortaleza. 11 de dezembro de 1954. as.: A. Ducke. 1p.

Documento 3

Após a conclusão da catalogação e sua digitalização em forma de verbetes, foram quantificados os documentos, e constatou-se que o acervo do projeto possui grande variedade de espécies documentais. São eles: 93 ofícios, 57 memorandos, 38 documentos iconográficos, 14 cartas, 14 matérias de jornais, 11 bilhetes, 11 documentos jurídicos, nove relatórios, três mapas, três inventários, três Artigos do Diário Oficial, três certificados, dois pareceres, dois planos diretores, dois formulários, um memorial, uma Lei, uma ordem de serviço, uma portaria, uma escritura de doação, uma taxa de emolumento, um título de doação, um recibo e uma procuração, como pode ser observado no gráfico (figura 7, a seguir). Neste gráfico pode ser constatado que os maiores índices de espécies documentais são de ofícios, seguido pelos memorandos e documentos iconográficos. Os menores índices, contendo apenas uma espécie documental, são memorial, lei, ordem de serviços, taxa de emolumento, título de doação, recibo e procuração.

Por fim, foram criados três índices, que são: remissivo, toponímico e antroponímico, organizados por ordem alfabética. No índice remissivo foram colocados os principais assuntos citados nos documentos, como criação, doação, silvicultura, entre outros. No índice toponímico foram incluídas as instituições citadas nos documentos, como Instituto Nacional de Pesquisas da Amazônia (Inpa), Conselho Nacional de Desenvolvimento Científico e Tecnológico (CNPq), entre outros. No terceiro

Ci. Inf., Brasília, DF, v. 39 n. 2, p.101-114, maio/ago., 2010
- JOBIM, Anísio. Aspectos Sócio-Geográficos do Amazonas: Adolfo Ducke. Manaus, s/d. Ed. Tipografia Fênix. Biografia de Adolfo Ducke. Documento 2

\section{VERBETE 2}


FIGURA 7

Quantidades e espécies documentais do arquivo
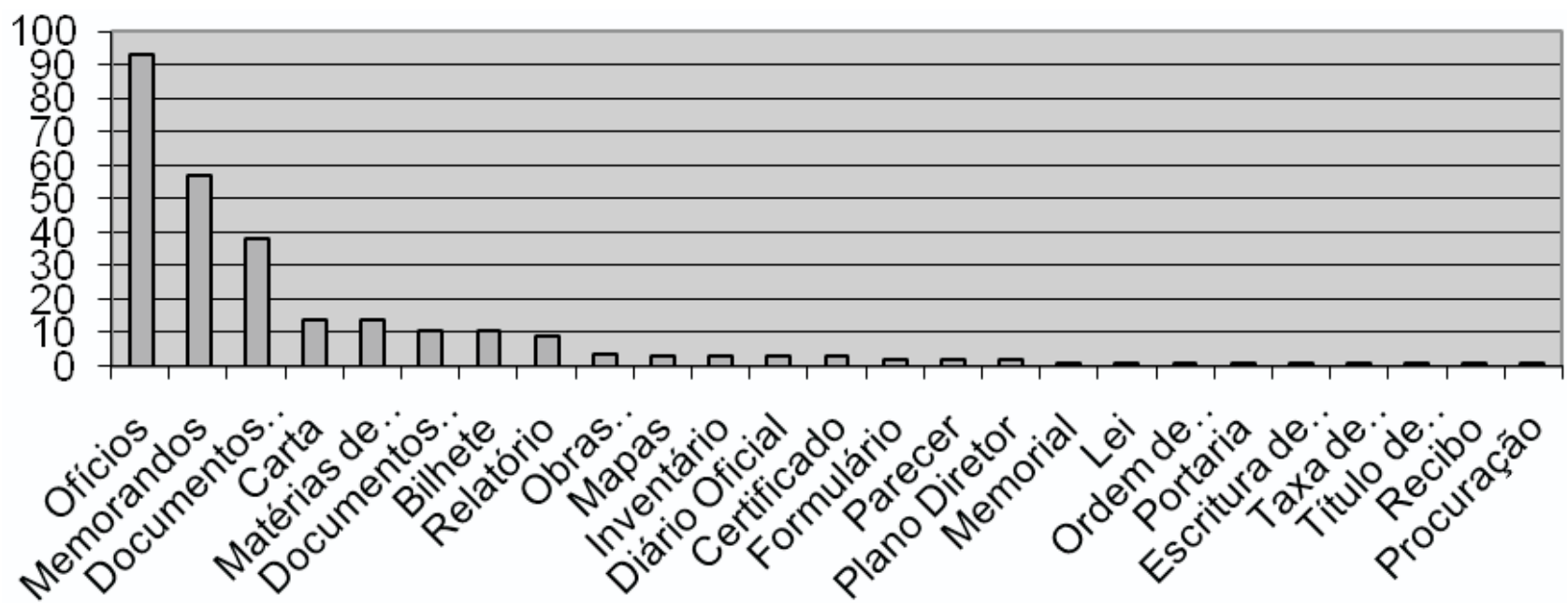

Fonte: AZEVEDO, Rodolfo Almeida de, e FREIRE, Eliane O. de Lima. Catalogo de Fontes Históricas da Reserva Florestal Ducke IN: Anais da XVIII Jornada de Iniciação Científica PIBIC CNPq/FAPEAM/Inpa. Manaus, CNPq, FAPEAM, Inpa, 20 a 24 de julho de 2009, pp. 713-716 (ver anexo 3).

e último índice, que é o antroponímico, foram colocados os personagens citados nos documentos, como Adolfo Ducke, Djalma Batista, William Rodrigues, entre outros.

\section{Catálogo Bibliográfico}

O catálogo bibliográfico recebeu como título "Catálogo de Teses de Doutorado e Dissertações de Mestrado Referentes a Reserva Florestal Ducke". Foi confeccionado com o objetivo de verificar, sistematizar e divulgar a produtividade científica referente à Reserva Ducke. Os dados catalogados foram quantificados. Com base neste levantamento, constatou-se que entre 1973 e 2006 foram produzidas 16 teses de doutorado e 54 dissertações de mestrado pelo Programa de Pós-Graduação Convênio Inpa e Universidade Federal do Amazonas (Ufam) entre 1973 e 2006. Na bibliografia identificada foram anotadas as referências, área do conhecimento e resumo. Todo o material foi digitalizado e organizado cronologicamente sob a forma de catálogo. Este catálogo encontra-se disponível on line na bome page:

http://ppbio.inpa.gov.br/Port/noticias/catalogo.

\section{ANÁlISE DO CONTEÚdO DAS PEÇAS DOCUMENTAIS DO ACERVO}

O acervo documental da Reserva Ducke oferece muitas de possibilidades de estudos temáticos com base no conteúdo dos documentos. Neste sentido, foram realizados alguns apontamentos temáticos das peças documentais, entre os quais se destacam: Adolfo Ducke, criação da reserva, infraestrutura, as pesquisas, ocupações ilegais, degradação versus preservação e jardim botânico.

\section{ADOLFO DUCKE}

O naturalista Adolfo Ducke aparece nas espécies documentais como importante figura no processo de criação da Reserva Florestal Ducke, inclusive em homenagem a ele a reserva recebeu seu nome. No acervo consta uma litografia de Adolfo Ducke datada de 1961, uma pequena biografia de 1950 escrita ainda em vida, que representa mais uma homenagem à figura do naturalista, enfatizando as passagens mais importantes da sua trajetória científica. Consta também a inédita correspondência de Adolfo Ducke destinada ao Inpa, quando lhe prestava assessoria científica. Trata-se de cartas, 
sendo 8 manuscritas e 5 datilografadas, dirigidas ao botânico William Rodrigues e ao diretor do Inpa Olympio da Fonseca. Em uma das cartas Adolfo Ducke orienta o Instituto quanto à localização da área para a possível criação da Reserva Ducke e fornece o mapa da localização da área. Este mapa também se encontra no acervo. Contudo, a documentação sobre a participação do Ducke no Inpa é bastante escassa. Talvez se conseguissem documentos mais precisos na biblioteca particular do próprio Adolfo Ducke (doada ao Inpa, por ordem de sua esposa, Josefina Ducke). Porém, a referida biblioteca foi destruída em um incêndio num barco no Rio Amazonas, justamente quando estava sendo transportada para o Inpa.

\section{CRIAÇÃO DA RESERVA}

A documentação referente à criação da Reserva Ducke é abundante, embora ainda não seja satisfatória. Entre os documentos mais importantes sobre o assunto, além da correspondência de Adolfo Ducke, existem os primeiros inventários da Reserva de autoria de Lechthler, que data de 1956. O segundo inventário é de autoria do engenheiro agrônomo Onety Soares, e que data de 1957; o terceiro tem autoria de Ruben Carvalho do Valle e data de 1960. Especificamente no relatório do inventário de Onety Soares são atestados os motivos do não aproveitamento da área escolhida pelo naturalista Adolfo Ducke. De fato, logo assim que a área indicada pelo Ducke foi localizada, constatouse que se encontrava bastante degradada pela ação do extrativismo. Somente numa segunda investida foi enfim localizada outra área de floresta primária. No relatório do inventário contém importantes registros do local, como a localização exata, sujeitos envolvidos, características gerais do bioma, dados florestais, um mapa, entre outros.

Sobre a criação da Reserva Ducke existem também os documentos oficiais. Trata-se de correspondências nas quais os diretores do Inpa solicitam ao governo do Estado do Amazonas a doação da referida área. $\mathrm{Na}$ documentação há fotografias dos principais atores envolvidos no processo de doação, entre os quais se destacam: Olympio da Fonseca, Arthur Reis, Djalma Batista e Plínio Coelho. Existe também a lei que oficializada a doação - Lei no 41 de 28 de novembro de 1962. Pela lei, o Estado, cujo governador era Plínio Coelho, fazia a doação de 100.000.000 $\mathrm{m}^{2}$ (cem milhões de metros quadrados) de terras situado no $\mathrm{km} 23$ da antiga Estrada de Campos Salles, ao Inpa. Além disso, existem ainda a Escritura e Título de Doação.

\section{INFRAESTRUTURA}

A infraestrutura da Reserva Ducke é um dos fatores principais para colocá-la entre as biotas mais bem estudadas do Brasil e sua construção pode ser visualizada em diversos documentos iconográficos. O acervo possui 38 documentos iconográficos, dentre os quais 29 mostram a construção dessa infraestrutura ao logo da década de 1960, mostrando a abertura das picadas e das primeiras trilhas, o desmatamento para construção dos alojamentos, a inauguração das bases, os pioneiros que auxiliaram na abertura das trilhas, entre outros assuntos. Dentre as imagens da Reserva Ducke estão cinco fotografias aéreas de sua área, de onde podem ser vistas as estradas, os alojamentos e a torre meteorológica.

A Reserva Ducke sofre muitas mudanças em seu território a partir da década de 1980, e essas transformações em sua infraestrutura são visíveis nos mapas da reserva, outra espécie documental de grande importância. Para se ter uma noção disso, nestes mapas são mostradas as quadrículas (trilhas) que a Superintendência da Zona Franca de Manaus (Suframa) fez em parte da área da Reserva Ducke, sendo até nos dias de hoje utilizada por pesquisadores que trabalham na reserva. Com base em dados de 1998, a Reserva possui uma torre de observação, uma estação meteorológica, um alojamento, 3 bases e um acampamento. Em 2000 foi inaugurado um jardim botânico denominado Jardim Botânico Adolpho Ducke, como pode ser observado em outra espécie documental que acompanhou esse evento: as matérias de jornais.

Ci. Inf., Brasília, DF, v. 39 n. 2, p.101-114, maio/ago., 2010 


\section{AS PESQUISAS}

As pesquisas na Reserva Ducke são de grande importância para o andamento da ciência na Amazônia, e não poderiam ficar de fora deste acervo, pois são o resultado das primeiras e últimas pesquisas que tiveram a Reserva Ducke como local de estudos científicos. A primeira pesquisa consiste em um inventário de Robert Lechthler, que tinha a finalidade de dar exata e possível base sobre a apreciação quantitativa e qualitativa da floresta dos arredores de Manaus. Este inventário foi feito seis anos antes da criação oficial da Reserva Ducke, indicando que bem antes de sua criação a reserva já era palco de pesquisas. Outro exemplo de pesquisa foi o inventário feito pelo engenheiro agrônomo Roberto Onety Soares, no qual descreve as principais espécies de valor econômico, a exemplo da copaíba, balata e pau-rosa.

As pesquisas se iniciaram com a silvicultura, cujo pioneiro foi o engenheiro agrônomo Rubem Carvalho do Valle, podendo ter sua imagem visualizada na documentação fotográfica do acervo. Ele também escreveu um inventário datado de 1960, contendo oito páginas onde são descritas árvores de baixios, chapadas e flancos, especificamente árvores de valor econômico. As atividades silviculturais desenvolvidas na reserva compreendiam estudos de regeneração artificial de espécies de alto valor econômico, manejo racional dos bosques, transformando matas heterogêneas de baixo valor em matas heterogêneas de alto valor. Estes estudos, juntamente com outros documentos, deram suporte à construção do "Plano Diretor da Reserva Florestal Ducke", de autoria de José Barros, Antônio Vieira, Jurandyr Alencar e Vivaldo Campbell. Esta peça documental de 1969 está também presente no acervo, e mostra a hidrografia, relevo, vegetação, clima e outros aspectos da Reserva, já pesquisados em projetos anteriores, objetivando conhecê-la, e consequentemente traçar planos para seu manejo futuro.

Os trabalhos silviculturais perduraram até 1972, e no ano seguinte as atividades de plantios foram encerradas e as pesquisas se concentraram no campo da taxonomia, dando inicio a uma nova fase na história da Reserva Ducke. No acervo documental existem fotografias de pesquisadores que se destacaram neste campo: William Rodrigues, Marlene Freitas e Byron Albuquerque. Os anos 1970 são marcados também pelo início de um projeto de grande importância para a história da reserva: tratase do projeto "Flora da Amazônia", cujo objetivo era catalogar as plantas existentes na Reserva Ducke, sendo publicado no ano de 1999 com o título "Flora da Reserva Ducke: guia de identificação das plantas vasculares de uma floresta de terra-firme na Amazônia Central". Outro resultado de pesquisa citado no acervo consiste no guia de cobras da Reserva Ducke, intitulado "Natural history of snakes in forests of the Manaus region, Central Amazônia", publicado em 1998.

\section{OCUPAÇÕES ILEGAIS}

Sobre as ocupações ilegais que ocorreram na reserva, os primeiros registros datam desde sua criação. O primeiro registro encontra-se no relatório do inventário florestal de Onety Soares, que denuncia a existência de uma estrada clandestina, construída na parte norte da futura reserva, provavelmente usada para a circulação de pessoas e escoamento dos materiais extraídos clandestinamente. A maior parte da documentação referente ao assunto são memorandos e ofícios, assim como processos de justiça. Nessa espécie documental observa-se que o interesse inicial na área era pelas madeiras de valor econômico, em detrimento das espécies de menor valor. A prática do extrativismo envolvia tanto empresas públicas como empresas privadas. A documentação existente no acervo não informa o desfecho dos processos na justiça que envolviam as questões da posse da terra pelas empresas. Em 1976 aparece o primeiro registro feito por posseiros, que visavam a executar no local atividades agrícolas. No acervo consta uma fotografia feita pelo pesquisador Antenor Pereira Barbosa, de 1990, que registra uma queimada ao lado sul da reserva, próximo ao Igarapé Ipiranga. 


\section{DEGRADAÇÃO VERSUS PRESERVAÇÃO}

A preservação das florestas é um assunto presente em várias espécies documentais, e os primeiros registros aparecem nas cartas. Estas peças são correspondências informais entre Adolfo Ducke e representantes do Inpa, nas quais é demonstrado grande interesse em preservar uma área da floresta Amazônica Central ainda virgem, ou seja, sem ter sido explorada pela ação humana, para servir de base de pesquisa, pois o Inpa nesse período era um instituto recém-criado e necessitava de um local para realizar suas atividades.

A primeira carta a trazer esse tema foi escrita por Adolfo Ducke endereçada a Olympio da Fonseca, então diretor do Inpa, datada de 11 de dezembro de 1954, dizendo que "para um botânico pesquisador, o obstáculo maior encontrado em Manaus é a enorme devastação da mata ao redor da cidade", dando a entender que desde esse período já havia a preocupação com a degradação das florestas. O mesmo assunto irá se repetir em outras cartas.

Outra peça documental a trazer esse tema é o relatório do inventário florestal de autoria de Onety Soares, que mostra forte interesse do Inpa em preservar uma área para protegê-la da grande exploração das florestas. Este documento foi anexado junto a outros que foram encaminhados ao Governo do Estado do Amazonas para auxiliar na justificativa de doação de terras ao Inpa. Nos ofícios, outra espécie documental, também é tratado este assunto, com um diferencial que é o extrativismo. Essa espécie documental só começa a se tornar frequente com a doação oficial da área da Reserva Ducke ao Inpa, a partir da década de 1970, quando o foco não é a questão da preservação das florestas de modo geral, mas sim de preservar uma reserva florestal de modo específico. Nesses documentos são abordadas outras questões, como ocupações ilegais, extrativismo, caçadores encontrados dentro dos limites da reserva.

\section{JARDIM BOTÂNICO}

Assuntos referentes ao Jardim Botânico Adolpho Ducke podem ser facilmente encontrados em uma espécie documental específica, as reportagens jornalísticas que acompanharam de perto todo seuprocesso de criação. Das 14 matérias de jornais pertencentes ao acervo, 10 tratam de assuntos referentes ao Jardim Botânico, como criação, invasões, os motivos que levaram à criação e outros assuntos relevantes para que se possa compreender todo o processo histórico. Entretanto, o Jardim Botânico de Manaus não é assunto exclusivo das matérias jornalísticas, podendo ser encontrado em outras espécies documentais, como é o caso de cartas datadas do ano de 1954, nas quais já é cogitada sua criação. São correspondências informais entre Adolfo Ducke e Olympio da Fonseca, na época diretor do Inpa, e os temas abordados são a localização do Jardim Botânico e da Reserva Florestal. Esses assuntos são mais frequentes no final da década de 1990, com as matérias e os ofícios que registraram as invasões na Reserva Ducke, principal motivo atestado para criação do Jardim Botânico dentro de uma reserva, objetivando conscientizar a população de seu entorno a não degradar a área verde. A atração de turismo para Manaus é considerada um dos fatores fundamentais para a construção de um jardim botânico na cidade, fator este que está presente em quase todos os documentos que fazem referência ao tema.

\section{CONCLUSÕES}

Por meio desta pesquisa evidenciou-se que os arquivos da Reserva Ducke até então não haviam passado por nenhum tratamento arquivístico. Graças à realização do projeto Resgate da História Sócio-Ambiental da Reserva Florestal Ducke, cópias dos originais de fontes documentais referentes à reserva foram recolhidas, reunidas e compiladas sob a forma de instrumentos de pesquisa. Dessa maneira foi possível compreender o processo de criação da Reserva Ducke, colocando em destaque a figura do seu idealizador, o naturalista Adolfo Ducke, além de revelar os bastidores da preparação dos caminhos para o desenvolvimento das pesquisas científicas, o resgate da memória dos pioneiros, da criação de sua infraestrutura, bem como o extrativismo e ocupações ilegais ali ocorridas.

Ci. Inf., Brasília, DF, v. 39 n. 2, p.101-114, maio/ago., 2010 
Salvaguarda do acervo documental da Reserva Florestal Ducke - Manaus-AM: registros de uma experiência

A partir deste trabalho fatos históricos foram resgatados e registrados para as futuras gerações. Porém observa-se ainda a ausência de registros mais concretos que permitam compreender com mais propriedade o caminhar da pesquisa científica na Reserva Ducke, que é um detalhe importante no processo de análise da documentação para o resgate da história desta reserva e preservação da memória patrimonial da história da ciência na Amazônia. Mesmo que o projeto já tenha reunido quantidade significativa de documentos, eles são ainda insuficientes para compreender com mais profundidade toda a trajetória percorrida, por exemplo as linhas e projetos de pesquisas, as instituições envolvidas e seus respectivos pesquisadores (brasileiras e estrangeiras), entre outros aspectos. Entretanto, precisa-se ainda, escarafunchar, remexer, enfim, procurar com mais insistência nos arquivos do Inpa, principalmente naqueles que ainda não foram consultados, documentos ou pistas mais esclarecedoras sobre este assunto.

Assim, espera-se que a elaboração destes instrumentos de pesquisa divulgue e facilite o acesso dos usuários aos documentos referentes à Reserva Ducke e consequentemente tragam à tona fatos ocultos e esquecidos ao longo da existência da reserva, que já serviu por tantas décadas como principal campo de pesquisa do Inpa. Os resultados deste trabalho poderão ainda auxiliar na orientação dos pesquisadores do Inpa na projeção das pesquisas futuras do Instituto. Além disso, espera-se também contribuir na resolução dos problemas ambientais que atingem o planeta Terra, principalmente, no que concerne à melhora da qualidade de vida, assim como a preservação da memória patrimonial da história da ciência na Amazônia, fator fundamental no processo de consolidação do desenvolvimento do Estado do Amazonas. Cópias dos originais das fontes documentais referentes à reserva foram recolhidas, reunidas e organizadas, visando a possibilitar a divulgação, o acesso e o manuseio dos documentos que servirão para futuros interessados na história e fundação da Reserva Ducke.

Artigo submetido em 11/09/2009 e aceito em 07/02/2011.

\section{REFERENCIAS}

ADIS, J. Amazonian Arachnida and Myriapoda. [S.1.]: Pensoft Pub. 2002.

ARAÚJO, Emanuel. Publicações de documentos históricos. Rio de Janeiro: Arquivo Nacional, 1985. (Publicações técnicas).

ARQUIVO NACIONAL (Brasil). Normas técnicas para transcrição e edição de documentos manuscritos. Rio de Janeiro, 2002. Disponível em: <www.portalan.arquivonacional.gov.br/Media/Transcreve.pdf.> Acesso em: 23 fev. 2009.

AZEVEDO, Rodolfo Almeida de. Catálogo de Fontes Históricas da Reserva Florestal Ducke. In: Relatório Final PIBIC/INPA. Manaus: CNPq, FAPEAM, INPA, 2009.

AZEVEDO, Rodolfo Almeida de.; FREIRE, Eliane O. de Lima. Catalogo de Fontes Históricas da Reserva Florestal Ducke. In: JORNADA DE INICIAÇÃO CIENTÍFICA PIBIC CNPq/ FAPEAM/INPA, 18., 20 a 24 de julho de 2009, Manaus. Anais... Manaus: CNPq, FAPEAM, INPA, 2009, p. 713-716.

BELLOTTO, Heloísa Liberalli. Como fazer análise diplomática e análise tipológica de documento de arquivo. São Paulo: Imprensa Oficial do Estado, 2002. (Projeto Como Fazer, 8). Disponível em: <www.arqsp.org. br/arquivos/oficinas_colecao_como_fazer/cf8.pdf.> Acesso em: 15 fev. 2009

Arquivos permanentes: Tratamento documental. Rio de Janeiro: Editora FGV, 2004.

CONSELHO NACIONAL DE ARQUIVOS (Brasil). Recomendações para digitalização de documentos arquivísticos permanentes. Rio de Janeiro, 2010. Disponível em: <http:/ /www.conarq.arquivonacional.gov.br/ cgi/cgilua.exe/sys/start.htm>. Acesso em: 02 jun. 2010.

CONSELHO INTERNACIONAL DE ARQUIVOS. IS AD $(G)$ : Norma Geral Internacional de Descrição Arquivística: adaptada pelo Comitê de Normas de Descrição, Estocolmo, 19-22 de Setembro de 1999. 2.ed. Lisboa: Instituto dos Arquivos Nacionais/ Torre do Tombo. 2002. Tradução de: Grupo de Trabalho para a Normalização da Descrição em Arquivo.

FREIRE, Eliane Oliveira de Lima; HIGUCHI, $\mathrm{M}^{a}$ Inês Gasparetto; AZEVEDO, Rodolfo Almeida de (Orgs.). Catálogo de teses de doutorado e dissertações de mestrado referentes à Reserva Florestal Ducke. Manaus: [s.n.], 2009. p. 81. Disponível em: <http://ppbio.inpa.gov.br/Port/ noticias/catalogo $>$.

FREIRE, Eliane Oliveira de Lima (Org.). Edição de Fontes Para a História Ambiental da Reserva Florestal Ducke. Manaus: [s.n.], 2009. p. 646. (Digitalizado).

GLÉNISSON, Jean. As publicações dos textos históricos. In: Introdução aos estudos históricos. São Paulo: Difel, 1961.

LIMA, Albertina Pimentel et al. Guia de sapos da Reserva Adolpho Ducke, Amarônia Central. Manaus: Áttema Design Editorial, 2006. 
Eliane Oliveira de Lima Freire / Rodolfo Almeida de Azevedo

MARTIINS, M.; OLIVEIRA, M. E. Natural history of snakes in forests of the Manaus region, Central Amazônia. Brazil. Herpetological Natural History, v.6, n.2, p. 78-150, 1998.

RIBEIRO, J. E. L. S. et al. Flora da Reserva Ducke: guia de identificação das plantas vasculares de uma floresta de terra firme na Amazônia Central. INPA: Manaus, 1999.

VITT, Laurie et al. Guide to the Lizards. Of Reserva Adolpho Ducke: Central Amazônia. Manaus: Áttema Design Editorial, 2008.
Agradecemos o apoio da Fundação de Amparo à Pesquisa do Estado do Amazonas (Fapeam), e o Conselho Nacional de Desenvolvimento Científico e Tecnológico (CNPq), pelo financiamento do projeto e a concessão da bolsa vinculada ao Programa de Desenvolvimento Cientifico Regional (DCR), sem os quais não seria possível a realização desta pesquisa. 